\title{
A Longitudinal Study on Activation to Behaviors of Reward
}

\author{
Lintao Wang ${ }^{1, *}$ \\ ${ }^{1}$ University of Illinois, Urbana-Champaign, Psychology, Urbana, IL, United States of America, 61801 \\ *Corresponding author. Email:Lintaow2@illinois.edu
}

\begin{abstract}
Many social and financial problems have reflected the importance of cultivating a healthy habit to perform good behaviors when humans are little in terms of receiving rewards. A longitudinal study for reward system will be presented in this paper through the concept of the incentive theory of motivation and expectancy theory. Humans would be motivated by the outside reinforcement. Two participants theoretically are selected to observe how their behaviors are impacted as changes in rewards, from first grade until they work in a company. Parents can utilize reward system to help their children to complete homework and obtain good grades, similarly, managers can utilize reward system to help their employees to increase their efficiency and productivity. Based on many previous investigations and analysis, a prolong research and discussion are made to explore the relationship exists between rewards and children/employees' performances, and list the potential explanations, implications, limitations, and future directions.
\end{abstract}

Keywords: incentive interventions, reward system, reinforcement, performances, motivation.

\section{INTRODUCTION}

Reward system functions in humans from early age through infants to adolescents and from adults to seniors. Giving candies to children as a reward could bring them a good behavior. Their desires for candies would keep them performing good behaviors. It is same for adults. Noone works for free in this world unless one is a saint. Motivation is an essential aspect to help human capital to reach job satisfaction. Rewarding employees is also significant in an organization as a kind of incentive means to coruscate their senses of honour and enterprise and accordingly increasing the company's output values. In such growth journey towards maturity, reward plays a decisive role in any stages of one's life. In past studies, many researchers theorize and investigate on the fields of effects of ages in terms of reward sensitivity [1], work performances and job strains relating to rewards [3], and changes in leader and subordinate behaviors based on rewards [2]. Plenty and various studies have been done; however, each of them is independent, no connection between the two; especially, once the previous study has been done, no further investigations and experiments are provided in the future. Thus, in this paper, the research will integrate and summarize previous experiments and further examine humans' incentives related with reward system throughout human life stages, childhood, adolescence, and adulthood with a longitudinal study. Hopefully, the research will explain the extinctions of how human understand the reward system in different human life stages and apply such pattern to motivate all work force to improve work initiative, work efficiency, and work productivity.

A theory behind reward system will be firstly evaluated and followed with a longitudinal study of reward system in different life stages, starting with childhood, ending with adulthood; the primary focus will be on adulthood with their work performance and work satisfaction.

\section{THE INCENTIVE THEORY OF MOTIVATION}

There are forces pushing humans to perform in certain ways and thus generating various behaviors. Such force could be internal as well as external. Mostly, it is the reason people solve tasks and achieve goals. In this section, behaviors influenced by external forces and desires of wanting reward (acting as an outside reinforcement as well) will be primarily discussed with the incentive theory of motivation.

The most well-known experiment related with the incentive theory of motivation is operant conditioning, which brings up the concept of incentive conventions, a 
relevant, a fully designed, and a scientific model. The behaviors are dictated by rewards or consequences, either to gain reinforcement or to avoid punishment. There is a term usually describing the process of operant conditioning, instrumental learning, which people would learn, or even most living beings would, through such process to prepare and to cultivate a habit. All steps and progress are necessary to understand operant conditioning in the effect of contributing a habit through powerful and orderly schedules [6]. In order to receive a desired behavior, beside properly setting up the learning process, a reward, an outside reinforcement is needed to motivate beings to act on the right direction. Take the easiest example of children, giving treats and good amount of allowances could motivate them to study and get good grades. Similarly, once they receive good grades, they would study hard at school. In addition, another example of the incentive theory of motivation is, which revealed as money and promotion. Such external rewards could motivate adults' behaviors (to work hard). Unpleasant and negative rewards will not be discussed in this paper. The above discussed treats, good grades, money, and promotion are rewards to motivate humans' behaviors; they function as incentive interventions. Only under incentive interventions and receiving favored consequences, the desired and good behaviors can be exposed or cultivated [4]. Furthermore, since rewards or incentives can help humans to engage in certain behaviors, it is crucial to adjust rewards; changes in the incentive theory of motivation was essential aspect of learning a habit. The rewards should be obtainable, and the goals should be accomplishable [5]. Otherwise, rewards have no influence on behaviors and humans will not be motivated. In order to retain a strong effect on motivating people, three factors play a huge role through this process, social, cognitive, and physical [5]. Once people change the object or the value of reward, the behavior would have a distinct difference. According to Frank Logan, for the same reward (incentive intervention), the present behavior would occur in a less independent or more independent rate comparing to the former behavior if researchers establish an experiment [5]. Furthermore, beside incentive interventions are changed over time, they could also be affected in different situations. From Stephen Franzoi, a professor at Marquette University in Wisconsin, introduces that receiving praises as incentive values from parents could bring an opposite behavior in different situations [7]. When one is alone at home, parents' praises could motivate his behavior to perform good consequences, which is a positive incentive; when his friends are with him at home, parents' praises may discourage his behavior and he may even resist the praises because his friends may tease him unfortunately [7]. In the second case, this child's behavior might be a bad one and it is unpredictable. It goes on his own way. Thus, properly forming and using a reward system for humans is an essential aspect to motivate them to perform in certain behaviors.

\section{A LONGITUDINAL STUDY DESIGN}

A longitudinal study is a research design that employs repeated observational measures of a particular individual over a short or a long period of time, exposed in natural setting, normally taking up to years or even decades, without any external effects or manual influences [8]. The longitudinal study design proposed in this paper does not involve any experimental factors; all rewards or incentive interventions are humans granted by themselves through their growth and life experiences.

When it comes to motivational research, a longitudinal study and a detailed approach should be combined in utilization to ensure obtaining full data from the participants [9]. Besides, in order to eliminate gender effect, two first grade students will be chosen, one male and one female, investigating from that starting time until 40 years old. Instead of focusing deeply on the entire duration of their life experiences, only favoring into several fatal life stages, such as childhood studying and adulthood working to observe, seeking whether in these two different stages, rewards could activate their good behaviors.

\subsection{Childhood Stage}

The two participants will go through similar experiences from the below discussions and hopefully will enjoy the benefits from reward system. Fortunately, during childhood, reward system can help humans to complete their homework and main good grades at school, even helping parents to do household duties. Poor student achievement is usually attributed to a lack of motivation and outside reinforcement; once the rewards are presented, such students would attempt to gain them so that eventually increase their motivation. Properly providing rewards could help students to grasp a healthy learning habit as they seek for the rewards. Sometimes, students would even learn the habit without knowing it. From Lori, Baranek, from Grand Valley State University, argues that good grades are actually the most common reward for students, not promises of giving stickers or treats because getting a good grade itself can motivate students to study hard [10]. However, all of them are good incentive interventions. From his discussed experiment, even though students who receive rewards do not have control over learning, they still have a big difference with the students who do not receive rewards on problem solving and task completing [10]. There is another study designed by Adriana Galvan, from the department of Psychology in the University of California at Los Angeles, focuses on using functional magnetic resonance imaging (fMRI) to investigate how reward system processing in adolescent in the ages of 7 to 11 with a reward magnitude task design and focusing on 
anticipation analysis [11]. From his finding, the reward seeking behavior is highly correlates with hyperresponsive dopamine system, which means the more rewards presented (or desired rewards), the better engagement performed from student [11]. Giving a more precise and more developed study designed by Leslie Hart from the University of Tennessee, to examine the impact of rewards for elementary students on the improvements of their writing skills through a single subject and structured, alternating treatments design with four participants. In the study of Leslie Hart, intervention stage with rewards given to them, students writing performances were improved, although not by much [16]. Such improvements were noted in production-dependent variables, TWW (Total Words Written) and CWS (Correct Writing Sequences) [16]. With the final measured values of PF (Performance Feedback) and PF+ (Performance Feedback plus reward), most participants demonstrate a clear increase in performance: optimus, from $57 \%$ to $85.7 \%$ in TWW and D.W. from $42.9 \%$ to $85.7 \%$ in CWS [16]. Across all participants, the values of TWW was $99.2 \%$ and CWS was $96.9 \%$, which exceeded the minimum standards of $80 \%$ [16]. No doubts, from the discussed studies and researches above, successfully and properly using reward system will generate the two participants' motivation and have a positive impact on result getting and effort putting, but reward value is not absolute; changes is reward value is very necessary when their parents and teachers utilize them. Obviously, providing rewards for these two participants to cultivate a healthy learning habit could lead them to a greater level of engagement to interact more with their teachers at school. As a result, they would persist that enthusiasm to complete tasks and retain good grades, and hopefully, they will stay motivated as long as the rewards presented.

\subsection{Adulthood Stage}

When the two participants grow up, they will find a job and work hard in an organization. At this time, they have been through childhood stages and learned the habit when they were little. Hopefully, the reward system motivated them through childhood and still will motivate them at work during adulthood stage. In an organizational setting, employees will be greatly influenced by reward system, normally referring to programs establishing by the company, on job efforts and work performance. In order to maximize employees' job efforts and work performances, the expectancy theory should be considered. Employers need to know what the employees need and make the notion that rewards would be only obtained upon their good performances [12]. In this case, employees would put more efforts into work. Besides, the need strength based on employees' desires should also be manipulated by managers to increase their productivity [12]. Furthermore, as earlier discussed in the paper, employees are normally enormously motivated with salaries, promotion, and vacations. Usually, promotion is often considered as an intrinsic reward; even though it is not tangible, it will actually lead to a much higher level of job satisfaction. All these rewards are substitutes provided by the organization in exchange of employees' efforts.

According to a descriptive and exploratory research design raised up by Francis and his colleagues, discovers that a positive relationship exists between rewards and employees' performances and retentions in the organization [13]. His finding supplements the above discussion, only employees love the environment created by the organization and the neighborhood of the organization's culture, employees would demonstrate a strong affective commitment so that they have retentions toward the company. Giving a succinct study on bank workers in Istanbul by Güngör, 116 bank employees in 12 global banks are analyzed in his study through an email survey. The questionnaire examined performances of employees through the following factors "quantity of output, quality of output, timeliness of output, presence at work, and cooperativeness" [15]. Based on his findings, those bank employees' performances in Istanbul are affected by financial rewards the most, instead of promotion as intrinsic rewards [15]. For getting such conclusion, Güngör used regression analysis with anova and coefficient models and an equation was discovered and illustrated, "Employee Performance $=0.806+0.692 *$ Financial Rewards" in terms of the $p$ value of 0.000 (coefficient significant) [15]. A positive relationship was found significantly between financial rewards and employee performances: for every increase in finial reward will contribute to increase in workers' performances. Anyway, as long as employees satisfy from their work itself and work environment, as well as receiving good compensation from the organization, they will work hard to achieve their goals and produce high productivities.

In terms of the two participants, they enjoyed the benefits of reward system in the organization. They put in their efforts to produce the best out of their performances. No matter either of them deserve the respect from the company and each time they complete a task and achieve one of the organization's goals, they are rewarded with prize. In the long term, their salaries are increased each year. Not all employees are like them that fits in with the reward system because the two participants were given rewards and understood rewards since they were a child. They know totally as long as they maximize their ability to work for the company, they would receive their expected rewards. Of course, companies love employees like our participants because they are easy to manage and produce quality work.

\section{CONCLUSION}

Even though it is difficult to conduct a longitudinal study for reward system from first grades to work, it is 
still necessary to do so because humans would learn a good and healthy habit from the reward system. It is a good advice to cultivate the habit through utilizing and adjusting rewards when humans are young from my research and all previous discussed articles and experiments. Totally, by doing such, parents can eliminate children's procrastinating behaviors and develop task solving and goal pursuing qualities. Beside benefits toward children, reward system as a reinforcement really solves many social and financial problem, especially in the organization. Through incentive interventions with its special direct and great effectiveness, most organizations will achieve success to maximum their profits [14]. Of course, the leadership management relates with reward system must be provided for employees because the most fundamental factor employees would desire is satisfaction. Do not think the research correlates with work and employees is useless; by doing such research, organizations can yield more products. Hopefully, after reading this paper, organizations may improve their reward system and care more about their employees. With the help of this study, all organizations will survive and be developed in the severe and intense competition environment. All the external factors will trigger both the organization and employees to grow, to be more efficient, to be more productive, and to achieve their goals.

There are several limitations in this study. The first limitation stems from our research design overall. It is just a proposal. It does not have many details of how to properly set up the research. It is mostly like an outline or a notion for the topic of reward system. Most materials discussed are background information and logic behind this longitudinal study proposal. Second, this study is lack of time. It is very time-consuming to conduct a longitudinal study. Researchers may not have time to observe participants over almost thirty years. Third, this study does not have any data to support the proposal. With better research opportunities, data collected from participants should be analyzed to ensure a more accurate conclusion.

Future research should consider the following limitations mentioned above and extend the study to my unexplored aspects, as well as conducting a more fully prepared, completed, and controlled research, avoiding the deficiencies the present study made. Hopefully, the future research could further my study, as well as examine and analyse on.

\section{AUTHORS' CONTRIBUTIONS}

This paper is independently completed by Lintao Wang.

\section{ACKNOWLEDGMENTS}

I would like to express my sincere gratitude to the following people for helping with this research project, without whom I would not have been able to complete this research. I am deeply grateful to my supervisor, Professor Henry Yin, from Duke University, for providing guidance and feedback. Thanks also to my TAs, for putting so many efforts on discussing this project and insightful comments and assistance at every stage of the research project.

\section{REFERENCES}

[1] Duijvenvoorde, A, Overgaauw, S Dahl, R, Macks, Z, A cross-sectional and longitudinal analysis of reward-related brain activation: Effects of age, pubertal stage, and reward sensitivity [J] Journal of Research Gate, 2014.

[2] Keller, T, Szilagyi, D, A longitudinal study of LEADER Reward behavior, subordinate expectancies, and satisfaction [J] Journal of Wiley Online Library, 2006.

[3] Shyman, E (n.d.), Examining mutual elements of the job STRAIN model and THE EFFORT-REWARD IMBALANCE model Among special EDUCATION staff in the USA - Eric SHYMAN [J] Journal of SAGE, 2011.

[4] Silverman, K, Jarvis, P, Jessel, J, \& Lopez, A Incentives and motivation $[\mathrm{J}]$ Journal of NCBI, 2016,

https://www.ncbi.nlm.nih.gov/pmc/articles/PMC51 31923/.

[5] Logan, A, Incentive theory and changes in reward. Psychology of Learning and Motivation [J] Journal of Science Direct, 2008, https://www.sciencedirect.com/science/article/pii/S 007974210860420X.

[6] Staddon, R, \& Cerutti, T, Operant conditioning [J] Journal of NCBI, 2003, https://www.ncbi.nlm.nih.gov/pmc/articles/PMC14 $73025 /$.

[7] Stephen, F, Psychology: A Discovery Experience, Cengage Learning; 1st edition, 2010.

[8] Caruana, J, Roman, M, Hernández-Sánchez, J, \& Solli, P, Longitudinal studies [J] Journal of thoracic disease, 2015, https://www.ncbi.nlm.nih.gov/pmc/articles/PMC46 69300/.

[9] Steel, P, Svartdal, F, Thundiyil, T, \& Brothen, T, Examining procrastination across multiple goal 
stages: A longitudinal study of temporal motivation theory [J] Jornal of NCBI, 2018.

[10] Baranek, L, The Effect of Rewards and Motivation on Student Achievement [J] 1996. https://scholarworks.gvsu.edu/cgi/viewcontent.cgi? article $=1292 \&$ context $=$ theses

[11] Galvan, A, Adolescent development of the reward system [J] Journal of NCBI, 2010. https://www.ncbi.nlm.nih.gov/pmc/articles/PMC28 $26184 /$.

[12] Mathibe, I, Expectancy Theory and its implications for employee motivation [J] 2008. https://scholars.fhsu.edu/cgi/viewcontent.cgi?articl $\mathrm{e}=1211 \&$ context $=$ alj.

[13] Francis, F, Oaya, Z, \& Mambula, C, Reward System as a Strategy to Enhance Employees Performance in an Organization [J] Journal of Research Gate, 2020.

[14] Yazdanifard, R, How a Proper Performance Related Reward System Can Contribute to Work Performance Excellence [J] Journal of Business and Management, 2014, Vol. 2(3):189-194.

[15] Güngör, P, The relationship between reward management system and employee performance with the mediating role of motivation: A quantitative study on global banks [J] Journal of Science Direct, 2011.

[16] Hart, A, L, The impact of rewards on the effectiveness of performance feedback in improving writing production in elementary school students [D] The University of Tennessee, 2017. https://race.tennessee.edu/cgi/viewcontent.cgi?refe rer=https://www.google.com/\&httpsredir=1\&articl e=5491\&context=utk_graddiss. 